\title{
Evaluation of Existing Layout Improvement and Creation Algorithms for Use in the Offsite Construction Industry
}

\author{
Chelsea RITTER $^{1 *}$, Beda BARKOKEBAS ${ }^{2}$, and Mohamed AL-HUSSEIN ${ }^{3}$ \\ ${ }^{1,2}$ PhD Student, Department of Civil and Environmental Engineering, University of Alberta \\ ${ }^{3}$ Professor, Department of Civil and Environmental Engineering, University of Alberta \\ ${ }^{*}$ Corresponding author's e-mail: critter1@ualberta.ca
}

\begin{abstract}
Construction is traditionally depicted as a labor-intensive industry which involves considerable inefficiency inherent to the common practices. Offsite construction offers a change to the current stigma, in which most of the work is transferred to a facility with a controlled environment and later transported to its destination, considerably reducing the amount of movement required by people and materials. Proper planning for such a facility is crucial for the success of offsite construction operations, since the effectiveness of such a space will determine the efficiency of the process and the quality of the final product. Several methods exist for layout creation and improvement in the manufacturing industry; however, there are advantages and disadvantages to using the different methods in an offsite construction facility. A review of the literature is conducted to summarize commonly used methods and respective considerations of each. The identified methods are then applied to an existing case study plant to create the optimized layout for each. The resulting layouts are then compared and evaluated based on the ease of transporting modules and components within the facility, and the estimated waste reduction and productivity increase. This evaluation will identify the usefulness of each method and identify common issues related to facility layouts that should be taken into consideration in future layout planning for offsite construction facilities.
\end{abstract}

\section{KEYWORDS}

Layout creation; Layout improvement; Waste reduction; Offsite construction

\section{INTRODUCTION}

Productivity of construction operations is of extreme importance due to the highly competitive environment, and the continued emphasis on schedule compliance and cost effectiveness (Park et al., 2005). Offsite construction allows for increased productivity automation, increased process control, and specialization of workers. In addition to improving productivity through improved processes, productivity can be improved through optimization of the facility layout. The Facility Layout Problem (FLP) addresses the influence that a plant layout has on the productivity and cost of operations in a manufacturing facility. It is estimated that improving the layouts of manufacturing facilities can reduce related costs by up to $30 \%$ (Tompkins et al., 1996). FLP, or 
site layout planning, has numerous applications, including in the chemical industry, electrical industry, food industry, and construction industry (Ojaghi et al., 2015; Said and El-Rayes, 2013; Xie and Sahinidis, 2008). The formulation of the FLP as a quadratic assignment problem was the first solution proposed by Koopmans and Beckman (1957). Formulation of the FLP as a quadratic assignment problem requires all departments (along with their sizes and possible locations) in the facility to be known, in addition to knowing the cost of locating a department in each specific location (Xie and Sahinidis, 2008), and is considered a special case as it requires all departments to be of equal size (Meller and Gau, 1996).

As a result of various FLP research, several algorithms have been proposed, including ALDEP (automated layout design program), CRAFT (Computerized Relative Allocation of Facilities Technique), and MULTIPLE (MULTI-floor Plant Layout Evaluation) (Meller and Gau, 1996). In recent years, more complex algorithms have been proposed to solve the problem such as genetic algorithms, particle swarm optimization, and ant colony optimization, (Pillai et al., 2011; Asl and Wong, 2017). Singh and Sharma (2006) point out that the solution for the optimal facility layout is heavily dependent on the production demand of the facility, which is not constant, thus the optimal layout produced by any algorithm may not be optimal for all operating periods.

\section{METHODS}

\section{Evaluation of layout improvement or construction methods}

As an initial investigation into the applicability of classic layout improvement and creation methods to offsite construction manufacturing, the following five methods are selected due their high acceptance from industry practitioners, easy implementation, and extensive use in different industries: (1) Quadratic assignment problem (QAP); (2) Computerized relative allocation of facilities technique (CRAFT); (3) Multi-floor plant layout evaluation (MULTIPLE); (4) Automated layout design program (ALDEP); and (5) Computerized relationship layout planning (CORELAP).

Of the tested methods, CRAFT is classified as an improvement method, meaning it requires an initial layout to start, while MULTIPLE, quadratic assignment, ALDEP, and CORELAP do not require an initial layout, and can thus be classified as construction methods, or used to recommend improvements to existing facilities. Each method may require different inputs, and no method is known to consistently produce the optimal layout. Each method may produce a different final layout, and it is up to the facility management to determine which layout will be the best for the facility being investigated.

Quadratic Assignment Problem (QAP). The Quadratic Assignment formulation has several limitations when applied to the FLP, resulting in difficulties in its implementation. These limitations include (1) the formulation, assuming that the flows between departments remain constant over the life of the facility (i.e., they are static) (Hosseini-Nasab et al., 2017); (2) the requirement for all departments to be of equal area; and (3) the departments must be of uniform shape (Zhou et al., 2017). The following formulas can be used to represent the QAP, where $i$ and $j$ are locations in the facility, $k$ and $l$ are departments, $f_{k l}$ represents the material flow between two 
departments, and $c_{i j}$ represents the cost of transporting materials between two locations (Koopmans and Beckman, 1957). The formulas for QAP represent each department being placed in only one location so that the cost of material flow (the cost of transportation multiplied by the frequency of the material flow between the departments) is minimized.

$$
\begin{aligned}
& \sum_{i=1}^{n} x_{i j}=1, \quad j=1,2, \ldots, n \\
& \sum_{j=1}^{n} x_{i j}=1, \quad i=1,2, \ldots, n \\
& x_{i j} \in\{0,1\}, \quad i, j=1,2, \ldots, n \\
& \min \sum_{k, l} \sum_{i, j} f_{k l} c_{i j} x_{k i} x_{l j} \quad \text { s.t. (1), (2), and (3) }
\end{aligned}
$$

Computerized relative allocation of facilities technique (CRAFT). CRAFT, proposed by Armour and Buffa (1963), aims to minimize the total cost of transporting materials between departments, which can be represented by Equation 5, where $k$ and $l$ are departments, thus $f_{k l}$ represents the material flow between two departments; $c_{k l}$ represents the cost of transporting materials between them; and $d_{k l}$ is the distance between them (often measured as rectilinear distance). CRAFT allows any departments which are adjacent to each other or that have the same floor area to be evaluated for switching. The savings of each possible exchange is calculated and the exchange that results in the highest savings is carried out. The process is repeated until there are no possible department exchanges that result in a savings, at which point it is considered that the optimal solution has been reached.

$$
\min \sum_{k=1}^{n} \sum_{l=1}^{n} f_{k l} c_{k l} d_{k l}
$$

Multi-floor plant layout evaluation (MULTIPLE). MULTIPLE, proposed by Bozer et al. (1994), requires input in the form of a conforming curve or space filling curve (SFC), a curve that is drawn through all grid spaces in a facility floorplan, which ensures that facilities are never split when the layout vector is applied (Drir et al., 2007). MULTIPLE is otherwise the same as the CRAFT algorithm, but because of the use of an SFC, MULTIPLE is useful for irregular facility shapes, facilities with multiple floors, or to ignore walkways and fixed departments. Unlike with CRAFT, MULTIPLE can exchange any non-adjacent departments to create a new layout. This is done by exchanging the departments in a layout vector and then determining the new layout by filling in the required department area along the SFC.

Automated layout design program (ALDEP). Seehof and Evans (1967) proposed ALDEP, which uses closeness relationships between the departments, department sizes (which are allowed to vary), and the facility shape and size as inputs to produce several final layout design options randomly selecting the first department and choosing adjacent departments based on the closeness ranking with the previously placed department. All of the created designs are then scored based on the department adjacencies present in the created layout to determine the optimal layout. ALDEP does not work well with irregularly shaped facilities, given that once the department vector is determined, the departments are placed in a vertical sweep pattern from one side of the rectangular facility to the other.

Computerized relationship layout planning (CORELAP). CORELAP was proposed by Lee and Moore (1967), and also requires the closeness relationships between the departments and 
department sizes (which are allowed to vary) as inputs. The algorithm produces one final optimized layout which will dictate the desired facility shape. A solution vector is produced by ranking the departments based on the total closeness rating (TCR), as seen in Equation 6, where $r_{i j}$ is the numerical value for the closeness relationship between a department and all other departments, and excludes departments that have an "undesirable" closeness relationship with the departments selected prior to them until the end of the vector. The departments are laid out from the solution vector starting from the center and moving outwards, which will often result in irregularly shaped facilities.

$$
T C R=\sum_{j=1, i \neq j}^{n} r_{i j}, \quad i=1,2, \ldots, n
$$

\section{Case study plant: current state}

The case study plant is located in Calgary, Alberta, Canada, and produces volumetric modules for multi-family homes as well as construction offices and accommodations. The modules are produced in a facility with nearly $75,000 \mathrm{ft}^{2}$ of production floor space and are fully finished when leaving the production facility. Prior to applying any layout improvement techniques to the facility, the current layout is mapped, and any information required for the layout improvement techniques is collected. Figure 1 presents the current layout of the factory.

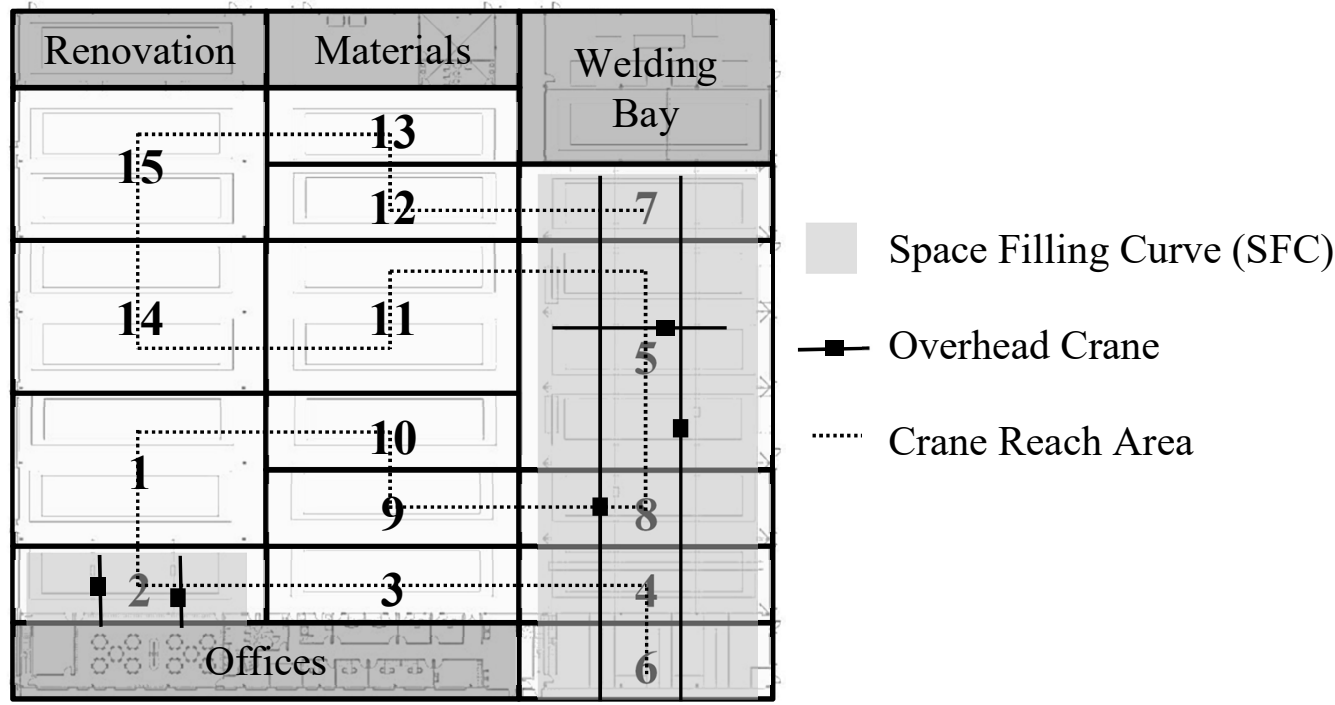

Figure 1. Current layout of the case study offsite construction facility.

The current layout of the plant is broken down into fifteen stations, as can be observed in Figure 1. The renovation bay, materials area, welding bay, and offices are not considered in the layout evaluation. The department names and floor area are presented in Table 1. There are several important characteristics of the case study plant that will influence the perception of different layout improvement methods as useful or not. First, the ceiling framing and drywall station is located on a mezzanine level, while all other departments are located on the main floor. This is important because while a larger department may be selected to be placed in this space and a space adjacent to it after the application of a layout improvement method, these departments are not actually adjacent because of the elevation distance, so there may be added transportation costs or other logistical concerns within or between the departments in this area. Another feature of the case study plant is the existing large infrastructure in the facility, including an exhaust 
system connecting to certain locations throughout the plant, and the existence of several overhead cranes, for which the building has been reinforced to support in the current locations. Certain departments (namely floor framing and sheathing, wall framing and drywall, ceiling framing and drywall, and assembly) require the use of these cranes and thus need to be located in locations that are accessible by the cranes. The locations of the overhead cranes are highlighted in Figure 1.

Table 1. Department names for case study plant.

\begin{tabular}{|c|c|c|c|c|c|}
\hline No. & Department Name & $\begin{array}{l}\text { Size } \\
\left(\mathbf{f t}^{2}\right)\end{array}$ & No. & Department Name & $\begin{array}{l}\text { Size } \\
\left(\mathbf{f t t}^{2}\right)\end{array}$ \\
\hline 1 & Carpentry Shop & 6,000 & 9 & Roofing & 3,000 \\
\hline 2 & Floor Framing and Sheathing & 3,000 & 10 & Exterior Insulation & 3,000 \\
\hline 3 & Floor Insulation and Sheathing & 3,000 & 11 & Exterior Finish and Windows & 6,000 \\
\hline 4 & Floor Finishing & 3,000 & 12 & Plumbing & 3,000 \\
\hline 5 & Wall Framing and Drywall & 9,000 & 13 & Electrical & 3,000 \\
\hline 6 & Ceiling Framing and Drywall & 3,000 & 14 & Interior Finish & 6,000 \\
\hline 7 & Precut & 3,000 & 15 & Fixture and Furniture & 6,000 \\
\hline 8 & Assembly & 3,000 & & Installation & \\
\hline
\end{tabular}

A layout improvement method that results in the recommended location for any of the stations requiring the use of an overhead crane not being within the identified crane pathways will require the company to invest in additional cranes or in other methods of flipping and lifting the large panels produced in those stations. This requirement will result in the necessity for a significant investment if the suggested optimal layout were to be implemented, and an analysis of whether the cost would be offset by any production improvements would need to be carried out.

\section{Possible application of improvement methods for offsite construction}

To better understand whether the application of any of the layout improvement methods outlined earlier are applicable to offsite construction manufacturing facilities, the possible implementation of the methods in the case study plant is investigated. To do this, the required inputs, including the relationship chart, department sizes, and facility size for the case study plant are collected. In the instances where existing plant layouts are required for the method (improvement methods), the existing facility layout is used as a starting point. A relationship chart detailing the level of necessity with which two departments should be placed adjacent to one another is required by several of the methods and is created for the case study plant.

Quadratic assignment problem $(Q A P)$. The requirement for QAP that all departments be uniform in size presents the first difficulty in applying this method to the case study plant. One possible solution to this issue is to break the larger departments down into smaller departments with an equal area of 3,000 $\mathrm{ft}^{2}$. While this solution allows the algorithm to be run, there is no available constraint to ensure that the newly spilt departments remain adjacent to one another and that the flow within the departments can be maintained.

Computerized relative allocation of facilities technique (CRAFT). The capability of CRAFT to allow departments of varying sizes makes this application much more useful than QAP; 
however, with no way to restrict the departments requiring a crane to be located under a crane path, the output of this method will not be economically feasible to implement. To apply CRAFT to the case study plant and account for the cranes, an additional constraint, which eliminates any exchanges that result in a department requiring a crane to be moved outside of the crane areas, is added. The algorithm is otherwise run as intended to produce the optimal layout.

Multi-floor plant layout evaluation (MULTIPLE). The SFC created for use with MULTIPLE is presented in Figure 1. Although MULTIPLE is similar to CRAFT, the creation of the new layout by applying the department areas in the order presented by the layout vector along the SFC again results in the inability to ensure that departments requiring overhead cranes remain in the crane path. A possible adjustment to ensure this is to run MULTIPLE for the case study plant as if it were two separate plants (once for the large crane area, and once for the remainder of the plant without overhead cranes). The single department overhead crane is treated as a fixed area in this variation.

Automated layout design program (ALDEP). The required input for the application of ALDEP to the case study plant includes the area of the facility, the area of the departments (Table 1), and a set sweep width, which dictates the column width with which the departments will be laid out. Since the plant is set up based on the maximum panel size, all oriented in the same direction, and all departments are approximately $100 \mathrm{ft}$ in length, a sweep width of $100 \mathrm{ft}$ is selected. The ability of ALDEP to allow for restricted areas is useful for the case study plant, as the renovation bay, materials area, welding bay, and offices can be set as restricted areas and not moved; however, ALDEP will also result in departments requiring an overhead crane being removed from the crane areas. To apply ALDEP to the case study plant, it is split into two smaller facilities, one comprising of the crane area, and another of the remainder of the facility.

Computerized relationship layout planning (CORELAP). Similar to the other methods discussed, CORELAP does not allow for the departments requiring an overhead crane to be restricted to the crane area. Moreover, the method for laying out the departments (working from the middle of the facility to the edges) causes difficulty in adjusting the algorithm to include this restriction. Because of this, the layout created by CORELAP would not be economically feasible for the case study plant to apply.

\section{RESULTS AND DISCUSSION}

Table 2 presents a summary of the research findings by addressing the suitability of each method for offsite construction. As is summarized in Table 2, QAP and CORELAP methods are not suitable for application to the case study plant due to their inability to maintain department relationships and access to overhead cranes, where required. The three remaining methods require modifications to ensure access to overhead cranes for some departments.

While it is possible to use some of the investigated layout improvement methods in the case study plant, the additional constraint of the existing overhead crane locations results in the need to consider the crane area and the remainder of the facility separately. This removes the possibility of accounting for the relationships between the departments that utilize the crane and those that do not. While a layout may appear to result in savings, an additional cost may be incurred over the interface between the two sections of the facility. Algorithms able to handle 
more constraints (i.e., particle swarm optimization, ant colony optimization, genetic algorithms) can be used to enable the consideration of additional constraints, but the setup time required for running these algorithms is considerably greater than for the methods presented in this paper.

Table 2. Department names for case study plant.

\begin{tabular}{lccl}
\hline \multicolumn{1}{c}{ Method } & $\begin{array}{c}\text { Suitability for } \\
\text { application to case } \\
\text { study plant }\end{array}$ & \multicolumn{1}{c}{ Reason } \\
\hline QAP & Not suitable & - & $\begin{array}{l}\text { Same size departments not ideal for case study } \\
\text { Unable to maintain department relationships }\end{array}$ \\
\hline CRAFT & $\begin{array}{c}\text { Suitable } \\
\text { (with modifications) }\end{array}$ & - & $\begin{array}{l}\text { Modification required to address overhead crane } \\
\text { requirements for some departments }\end{array}$ \\
\hline MULTIPLE & $\begin{array}{c}\text { Suitable } \\
\text { (with modifications) }\end{array}$ & - & $\begin{array}{l}\text { Modification required to address overhead crane } \\
\text { requirements for some departments }\end{array}$ \\
\hline ALDEP & $\begin{array}{c}\text { Suitable } \\
\text { (with modifications) }\end{array}$ & - & $\begin{array}{l}\text { Modification required to address overhead crane } \\
\text { requirements for some departments }\end{array}$ \\
\hline CORELAP & Not suitable & - & Difficult to modify for crane restriction \\
\hline
\end{tabular}

The current case study plant operates with minimal automation and high use of overhead cranes. This is a limitation in the comparison of the methods, as other facility plans may introduce other restrictions that would change the effectiveness of the evaluated methods.

The knowledge of the facility workforce, including managers and production workers, should not be overlooked when considering layout optimization. Their knowledge, which can be gathered through interviews and focus groups, may be capable of developing a near optimal facility layout plan that considers multiple complex constraints and is able to be implemented in the facility. In the future, this knowledge can be implemented in the optimization through methods such as Analytic Hierarchy Process (AHP).

\section{CONCLUSION}

This research presents a comparison of some widely used methods for the FLP. Their relatively simple implementation and significant possible improvements to the facility's layout creates an interest in offsite construction practitioners interested to increase its productivity; however, it is clear that any of these methods are not ready for implementation in the industry without modifications. CRAFT, MULTIPLE and ALDEP methods fail to incorporate the use of overhead cranes, a required equipment in any modular construction facility, so modification of the method is required. Other algorithms (i.e., particle swarm, ant colony, etc.) are able to incorporate features such as the use of overhead cranes, but the requirement for more detailed input and a more demanding implementation pose a barrier for initial layout assessments.

Thus, this research recommends the adaptation of the identified methods to incorporate required features for the context of offsite construction as a solution to address initial concerns and planning of offsite construction facilities. These results can later be compared with other more complex algorithms in order to address their effectiveness and quantify the tradeoff between the results received and effort required to perform the analysis. 


\section{ACKNOWLEDGEMENTS}

The authors would like to thank C\&V Smart Structures for allowing observation and mapping of their facility. This research is funded by the NSERC Industry Research Chair Grant.

\section{REFERENCES}

Armour, G.C., and Buffa, E.S. (1963). "A heuristic algorithm and simulation approach to relative allocation of facilities." Management Science, 9(2):294-300.

Bozer, Y.A., Meller, R.D., and Erlebacher, S.J. (1994). "An Improvement-Type Layout Algorithm for Single and Multiple-Floor Facilities." Management Science, 40(4):918:932.

Asl, A.D., and Wong, K.Y. (2017). "Solving unequal-area static and dynamic facility layout problems using modified particle swarm optimization." Journal of Intelligent Manufacturing, 28(6):1317-1336.

Drira, A., Pierreval, H., Hajri-Gabouj, S. (2007). "Facility layout problems: A survey." Annual Reviews in Control, 31:255-267.

Hari Prasad. N., Rajyalakshmi. G., and Sreenivasulu Reddy, A. (2014). "A Typical Manufacturing Plant Layout Design Using CRAFT Algorithm.” Procedia Engineering, 97:1808-1814.

Hosseini-Nasab, H., Fereidouni, S., Ghomi, S.M.T.F., and Fakhrzad M.B. (2017). "Classification of facility layout problems: a review study." International Journal of Advanced Manufacturing Technologies, 94:957-977.

Koopmans, T.C., and Beckman, M. (1957). "Assignment problems and the location of economic activities." Econometrica, 25, 53-76.

Lee, R., and Moore, J. M. (1967). "CORELAP-computerized relationship layout planning." The Journal of Industrial Engineering, 18:195-200.

Meller, R.D., and Gau, K. (1996). "The facility layout problem: Recent and emerging trends and perspectives." Journal of Manufacturing Systems, 15(5), 351-366.

Park, H.S., Thomas, S.R., and Tucker, R.L. (2005). "Benchmarking of Construction Productivity." Journal of Construction Engineering and Management, 131(7):772-778.

Pillai, V.M., Hunagund, I.B., and Krishnan, K.K. (2011). "Design of robust layout for Dynamic Plant Layout Problems." Computers \& Industrial Engineering, 61:813-823.

Said, H. and El-Rayes, K. (2013). "Performance of global optimization models for dynamic site layout planning of construction projects." Automation in Construction, 36, 71-78.

Seehof, J.M., and Evans, W.O. (1967). "Automated layout design program." The Journal of Industrial Engineering, 18:690-695.

Singh, S.P., and Sharma, R.R.K. (2006). "A review of different approaches to the facility layout problems." International Journal of Advanced Manufacturing Technology, 30:425-433.

Tompkins, J. A., White, J. A., Bozer, Y. A., Frazelle, E. H., Tanchoco, J. M. A., and Trevino, J. (1996). Facility planning (2nd ed.). New York: John Wiley \& Sons, Inc.

Xie, W., and Sahinidis, N.V. (2008). "A branch-and-bound algorithm for the continuous facility layout problem." Computers \& Chemical Engineering, 32(4-5), 1016-1028.

Zhou, J., Love, P.E.D, Teo, K.L., and Luo, H. (2017). "An exact penalty function method for optimising QAP formulation in facility layout problem." International Journal of Production Research, 55(10):2913-2929. 